\title{
Trichosanthes cucumerina extracts enhance glucose uptake and regulate adiponectin and leptin concentrations in 3T3-L1 adipocytes model
}

\author{
${ }^{1 *}$ Sassi, A., ${ }^{1}$ Khattak, M.M.A.K. and ${ }^{2}$ Taher, M. \\ ${ }^{1}$ Nutrition Department, Kulliyyah of Allied Health Sciences, IIUM Kuantan Malaysia \\ ${ }^{2}$ Pharmaceutical Technology Department, Kulliyyah of Pharmacy, IIUM Kuantan Malaysia
}

\section{Article history:}

Received: 19 September 2017

Received in revised form: 16

October 2017

Accepted: 19 October 2017

Available Online: 21 October 2017

\section{Keywords:}

Trichosanthes cucumerina,

3T3-L1,

Adipogenesis,

Adipolysis,

Glucose uptake,

ELISA

\section{DOI:}

https://doi.org/10.26656/fr.2017.2(2).230

\begin{abstract}
Trichosanthes cucumerina (Cucurbitaceae) commonly known as Snake gourd or Labu Ular is considered the largest genre in the Cucurbitaceae family and is mainly found in the southeast areas of Asia. It has been used in Ayurvedic medicine as a treatment for certain diseases such as Diabetes mellitus, but these acclaims lack scientific-based evidence. In this study, water and ethanol extracts of three parts of Trichosanthes cucumerina namely; whole vegetable, peels, and seeds, were assessed for toxicity through a cell viability assay using 3T3-L1 pre-adipocytes model which revealed a maximum toleration concentration of $0.063 \mathrm{mg} / \mathrm{mL}$. The extracts were further tested on adipocytes' differentiation and positively showed a stimulation of lipid droplets formation during adipogenesis and significantly $(\mathrm{p}<0.001)$ increased glycerol release levels $(75.34 \pm 3.69 \mu \mathrm{g} / \mathrm{ml})$ during adipolysis. The extracts also significantly $(\mathrm{p}<0.001)$ promoted the uptake of glucose into the cells $(2636.22 \pm 91.33 \mathrm{~Bq})$ in an action similar to that of insulin. Similar results were observed during ELISA assay with a significant increase $(\mathrm{p}<0.001)$ in adiponectin concentrations $(3593.1 \pm 225.25 \mathrm{ng} / \mathrm{mL})$ and a decrease in leptin concentrations $(23870 \pm 5066.07 \mathrm{pg} / \mathrm{mL})$. The present study results indicate a beneficial effect of Trichosanthes cucumerina extracts on adipogenesis, adipolysis and glucose uptake, in addition to a regulation of adiponectin and leptin concentrations in 3T3-L1 adipocytes which can be of clinical importance in energy regulation which is a key factor in treating diabetes, obesity, and metabolic syndrome.
\end{abstract}

\section{Introduction}

Despite the immense breakthrough in medicine and the wide variety of treatments available in the market, it remains a basic fact that good nutrition is the single cost effective way to improve health and well-being and avoid side effects, the failure of long term desirable results and the economic burden resulting from the use of drugs (Wang et al., 2013). Vegetable consumption is considered an integral part of the daily human diet in all cultures around the world. Fruits and vegetables represent excellent sources of nutrients such as vitamins, minerals, dietary fiber and antioxidants (Kader, 2001). A fruit and vegetable-rich diet have been promoted since the early ages where it has been consumed as whole or segmented such as seeds, leaves, roots, and tubers. Long term consumption of fruits and vegetables may be protective in nature from certain diseases such as cancer (Roleira et al., 2015), cardiovascular disease (Hu, 2011), obesity (Newby, 2009), Diabetes Mellitus (particularly Type 2 Diabetes) (Zaklos-Szyda et al., 2015), gastrointestinal disorders (Floch and Hong-Curtiss, 2002) and several other diseases. Diabetes Mellitus (T2DM) has become one of the common targets for treatment using plant foods and traditional herbal remedies due to its fast expansion and spread throughout the world. It has been reported that around 1300 species claim to possess antidiabetic properties (Patel et al., 2012) which shed the light for researchers to investigate and provide scientific-based validation of these species and the effect of their phytochemicals on a variety of diseases especially $\mathrm{T} 2 \mathrm{DM}$.

Among these acclaimed medicinal plants in Asia generally, and Malaysia particularly, is the Cucurbitaceae family which, despite its abundance and availability, has been poorly investigated for its potential benefits on modern health diseases. The vegetables from this family, also called gourds, are considered nutritionally beneficial due to their high water and fiber content as well as the high amount of vitamin content such as $\mathrm{A}, \mathrm{K}$, and $\mathrm{C}$, minerals like potassium and 
antioxidants (Chunduri, 2013). One of the largest genres in the Cucurbitaceae family (comprising of 22 species mainly found in the southeast areas of Asia) is Trichosanthes cucumerina, commonly known as Snake gourd or Labu Ular, which is a vegetable that is highly consumed in the Malaysian diet for its high water content and richness in vitamin $\mathrm{C}$ and proteins. It has been used in Ayurvedic medicine as a treatment for headache, fever, abdominal tumours and skin allergies (Saboo et al., 2013). The water and ethanol extracts of Trichosanthes cucumerina whole vegetable (TCW), peels (TCP) and seeds (TCS) were investigated in this study for their effect on 3T3-L1 adipocytes differentiation, adipolysis, glucose uptake in addition to adiponectin and leptin concentrations.

\section{Materials and methods}

\subsection{Chemicals}

Cell culture chemicals were obtained from Gibco life technologies MA, USA, while the 3T3-L1 preadipocyte cells (derived from mouse embryonic fibroblasts) were purchased from American Type Culture Collection (ATCC) Virginia, USA. Adipogenesis chemicals were obtained from SIGMA Aldrick Co. MO, USA. MTT and adipolysis kits were obtained from Cayman Co. Michigan, USA.

\subsection{Acquisition of vegetables}

Fresh vegetables of Trichosanthes cucumerina were purchased from a local market in Kuantan, Pahang, Malaysia and identified by the Department of Pharmacology, Kulliyyah of Pharmacy, International Islamic University of Malaysia.

\subsection{Preparation of extracts}

\subsubsection{Water extraction}

The extraction was performed according to a method described by Chen et al. (2003). $300 \mathrm{~g}$ of fresh and mature Trichosanthes cucumerina vegetables were washed thoroughly with tap water and separated manually into three parts: whole vegetable (TCWw), peel (TCPw) and seed (TCSw). An electric juicer (Philips HR 7620) was used to extract the juice using distilled water $(300 \mathrm{~mL})$. The green juice obtained was centrifuged then filtered using a Buchner flask and the clear greenish solution obtained was frozen and completely lyophilized through a continuous freezedrying operation for 72 hours (Christ Alpha 1-4 LSC, UK). The procedure was repeated for each part of the vegetable accordingly. The TC powder obtained was weighed and the extraction yield was calculated. The total extracted Yield ranged from 6-16\% wherein the lowest yield being in the seeds, the powder was then kept in airtight containers at $-40^{\circ} \mathrm{C}$ until further use.

\subsubsection{Solvent extraction}

The solvent extraction was used following a method previously described by Mujahid et al. (2013). The vegetables were washed thoroughly with tap water and weighed in a portion of $300 \mathrm{~g}$ each and separated into whole vegetable (TCWe), peel (TCPe) and seed (TCSe). The vegetable sizes were reduced into $1 \mathrm{~cm}^{3}$ pieces and dried for 3-5 days in an oven (OV 50, GenLab, UK) at $37^{\circ} \mathrm{C}$. The dried vegetables were collected and powdered using an electric grinder (Philips HL7610, Germany) and the powder was further macerated in ethanol 99\% (600 $\mathrm{ml}$ per day) for three consecutive days. The solution obtained was filtered and concentrated in a rotary evaporator (IKA 115, Cole Parmer, IL, USA) to yield an ethanol-free extract. These extracts were then weighed and the yield percentages were calculated which ranged from $10-25 \%$ wherein the lowest yield showed in the seeds, the extracts were then kept in airtight containers at $-40^{\circ} \mathrm{C}$ until further use.

\subsection{MTT assay}

Seeded cells with test compounds and DMSO as a negative control were incubated for $72 \mathrm{~h}$ then treated with $10 \mu \mathrm{l}$ of MTT solution $(5 \mathrm{mg} / \mathrm{mL})$ followed by an incubation for $4 \mathrm{~h}$ in the dark. A vivid purple color was depicted after the addition of DMSO to the wells. The absorbance was measured right away using a microplate reader (Tecan Infinite 200 PRO NanoQuant) at a wavelength of $570 \mathrm{~nm}$ and a reference wavelength of $630 \mathrm{~nm}$ (Meerloo et al., 2011).

\subsection{Oil Red O staining}

The preadipocytes differentiation procedure was performed following a method described by (Zebisch et al., 2012). A cocktail combination of insulin, IBMX and Dexamethasone were used to differentiate pre-adipocytes seeded in a 96 well plate into mature adipocytes. Vegetable extracts were introduced to the cells prior to the induction to observe the effect on the differentiation. Once the lipid droplets were visible the cells were stained using a $0.1 \%$ working solution of Oil Red O dye and left for 2 hours at room temperature following the method described by (Rizzatti et al., 2013). The wells were then washed using $\mathrm{ddH}_{2} \mathrm{O}$ until no reddish color emerged from the washing solution. Triton $\mathrm{x}-100$ in isopropanol was used as a dye extraction solution then a measurement of the absorbance was performed in triplicate at $520 \mathrm{~nm}$ using a microplate reader.

\subsection{Adipolysis}

A kit was used for the measurement of glycerol release in fully differentiated adipocytes. Test compounds were introduced to the cells after their differentiation and incubated for $1 \mathrm{~h}$ using isoproterenol as a positive control and fresh DMEM as a negative 
control. The supernatant of each well was then retrieved and transferred into new wells and free glycerol assay reagent was added followed by incubation for 15 minutes at room temperature. The absorbance was measured in triplicate at $540 \mathrm{~nm}$ using a microplate reader.

\subsection{Glucose uptake}

Mature 3T3-L1 cells were cultured in 24 well plates and serum-starved in a $1 \mathrm{~mL} /$ well serum-free media for 4 $\mathrm{h}$ at $37^{\circ} \mathrm{C}$ then they were washed and incubated with 1 $\mathrm{mL} /$ well of KRPH for $30 \mathrm{mn} / 37^{\circ} \mathrm{C}$. Vegetables' extracts along with insulin were added $30 \mathrm{mn}$ prior to addition of the radiolabeled glucose. 2-deoxyglucose $(0.001 \mathrm{mM})$ was used together with the radiolabeled tracer, 2-deoxy$\mathrm{D}$-[1,2-3H]-glucose $(0.037 \mathrm{MBq})$ to give a concentration of $0.2 \mathrm{mM}(0.5 \mathrm{mCi} / \mathrm{mmol})$ yielding an activity of 0.1 $\mathrm{uCi} / \mathrm{mL}$. The glucose uptake procedure was terminated by washing the wells three times with ice-cold PBS (Ph 7.4) then the cells were washed and lysed with $0.7 \mathrm{~mL}$ of $1 \%$ Triton X-100 for $40 \mathrm{mn} / 37^{\circ} \mathrm{C}$ (Yamamoto et al., 2011). The counting of each sample from each lysate was performed using a liquid scintillation counter (Packard Tricarb 2700 TR/SL liquid scintillation analyzer, Packard instrument CO) where all measurements have been performed in triplicate.

\subsection{Adiponectin and leptin concentrations}

The enzyme-linked immunosorbent assay (ELISA) mouse kits specific for adiponectin or leptin (Cayman Co. Michigan, USA) were used for the determination of their concentration levels in cell supernatants which were collected from mature adipocytes. The assay was performed according to the manufacturer's protocol. 100 $\mu \mathrm{l}$ of the sample previously diluted was added to the wells of a 96 well plate previously coated with a pretitered amount of anti-mouse adiponectin/leptin monoclonal antibodies and $10 \mu 1$ of insulin was added as a positive control while the wells for the negative control contained fresh media only. The well plate was incubated for 2 hours at $37^{\circ} \mathrm{C}$ then the liquid was removed without washing the wells. $100 \mu$ l of Biotin antibody was added to each well followed by incubation for

1 hour at $37^{\circ} \mathrm{C}$, the liquid was then aspirated and the wells were washed three times. $100 \mu$ of HRP-Avidin (avidin horseradish peroxidas) was added to each well followed by incubation for 1 hour at $37^{\circ} \mathrm{C}$ and a five time washing procedure. TMB substrate $\left(3,3^{\prime}, 5,5^{\prime}-\right.$ Tetramethylbenzidine) is then added to each well followed by incubation in the dark for 15-30 mn. Finally, $50 \mu \mathrm{l}$ of stop solution was added to each well and the absorbance was measured right away at $450 \mathrm{~nm}$. All measurements were performed in triplicate.

\subsection{Statistical analysis}

Results were expressed as mean \pm standard deviation of at least three independent replicates. The data collected was subjected to the one-way analysis of variance (ANOVA) using SPSS version 20, followed by Tukey's post hoc test to ascertain differences in the means at $95 \%$ confidence interval $(\mathrm{P}<0.05)$.

\section{Results and discussion}

\subsection{MTT assay}

MTT analysis showed that the treatment of 3T3-L1 preadipocytes with water and ethanol extracts of Trichosanthes cucumerina had a concentrationdependent cytotoxic effect where the proliferation increased when the extracts concentration was reduced. The concentration of $0.063 \mathrm{mg} / \mathrm{mL}$ showed no effect on cell viability in all extracts as shown in Figure 1. Concentrations from 0.125 to $1 \mathrm{mg} / \mathrm{mL}$ seemed rather toxic for the cells and reduced their viability. Ethanol extracts (TCWe, TCPe, TCSe) caused lower proliferation of the cells compared to water extracts due to the fact that ethanol is a solvent for both acidic and basic constituents and provides a wide range of compounds from different polarities since it has both polar and nonpolar characteristics. The tetrazolium ring found in the tetrazolium salt MTT is reduced to formazan by mitochondrial succinate dehydrogenase found in active living cells. This forms a purple precipitate in the mitochondria where the amount of precipitate formed is proportional to a number of living cells (Riss et al., 2004). The Cucurbitaceae family is known to contain toxic compounds called Cucurbitacins which are a class of highly oxidized tetracyclic triterpenoids that are widely distributed in the plant kingdom especially in the Cucurbitaceae family from which they were originated. These Cucurbitacins are responsible for the plants' bitterness which increases by the increase in the Cucurbitacin content (Kaushik et al., 2015).

\subsection{Oil red O staining}

Trichosanthes cucumerina extracts significantly induced differentiation in 3T3-L1 cells and stimulated the formation of lipid droplets compared to the nontreated control cells as shown in Figure 2. Lipid droplets are visible after a staining procedure using Oil red $\mathrm{O}$ dye wherein the intensity of the color is proportional to the number of differentiated cells (Rizzatti et al., 2013). A study by Gry et al. (2006) showed that Trichosanthes cucumerina contains a Cucurbitaceae known as cucurbita -5,24-dienol that could be responsible for stimulating adipogenesis in adipocytes, this study was backed up by Arawwawala et al. (2009) which reported the presence of Cucurbitacins such as triterpenoids which could act synergistically to stimulate adipogenesis.

\subsection{Adipolysis}


Trichosanthes cucumerina extracts significantly $(p<0.001)$ increased glycerol concentrations in all

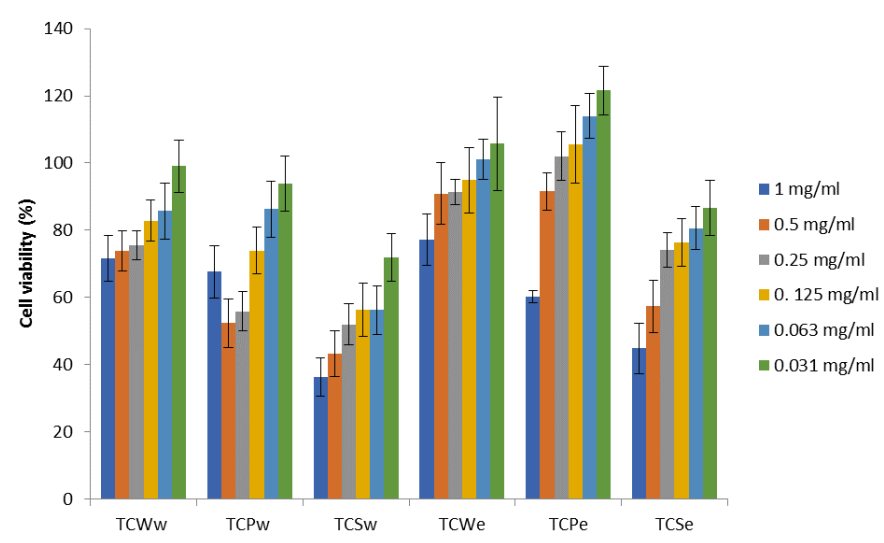

Figure 1. Effect of different concentrations of Trichosanthes cucumerina water and ethanol extracts on the proliferation of 3T3-L1 preadipocytes (MTT assay)

extracts in 3T3-L1 cells and showed the highest concentrations of glycerol in the ethanol extracts of the vegetable TCWe $(75.34 \pm 3.69 \mu \mathrm{g} / \mathrm{ml})$ which were closer in value to the positive control isoproterenol $(83.76 \pm 5.15$ $\mu \mathrm{g} / \mathrm{ml}$ ) compared to the water extracts (TCWw) which were relatively lower as shown in Figure 3. The extracts of the peels and seeds showed similar results with higher concentrations in the ethanol extracts (TCPe, TCSe) compared to the water extracts (TCPw, TCSw). Adipolysis is the breakdown of accumulated triglyceride stores in differentiated adipocytes during energy deprivation by releasing glycerol and free fatty acids. This process is achieved by sequential action of adipose triglyceride lipase (ATGL), hormone-sensitive lipase (HSL) and monoglyceride lipase (MGLL) through the production of cAMP (cyclic Adenosine Monophosphate) which subsequently activates PKA (Protein Kinase A)

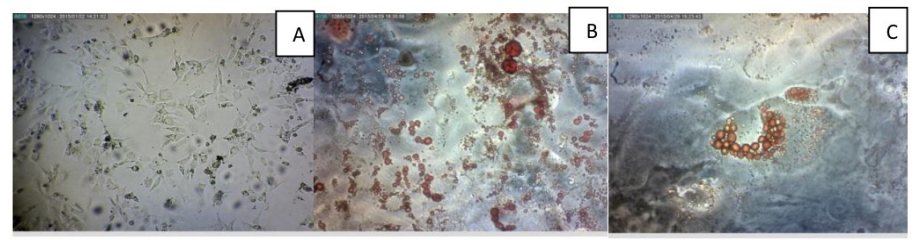

Figure 2. (A): Undifferentiated 3T3-L1 preadipocytes used as a negative control (Mag. 100x). (B): differentiated 3T3-L1 adipocytes stained with Oil Red $\mathrm{O}$ dye used as a positive control (Mag. 100x). (C): Mature adipocyte stained with Oil Red O (Mag. 200x).

which is considered the main stimulator of lipolysis (Nielsen et al., 2014). According to Harmon and Harp (2001), flavonoids possess the ability to induce lipolysis in 3T3-L1 adipocytes. This has also been reported by Rayalam et al. (2008), elucidating that several natural compounds found in Cucurbitaceae extracts, such as polyphenols and flavonoids, stimulate lipolysis by increasing cAMP and PKA in 3T3-L1 adipocytes. According to Adebooye (2008), Trichosanthes cucumerina pulp contains high amounts of ascorbic acid, lycopene, phenolics, flavonoids, and antioxidants.
Separated extracts (TCP, TCS) will eventually contain lesser amounts and therefore, will have a lower effect compared to the whole vegetable.

\subsection{Glucose uptake}

Trichosanthes cucumerina extracts significantly $(p<0.001)$ stimulated glucose uptake in adipocytes in an action similar to insulin with the highest value shown in ethanol extracts such as TCWe $(2636.22 \pm 91.33 \mathrm{~Bq})$ which was very close in value to the positive control insulin $(2692.17 \pm 272.15 \mathrm{~Bq})$ as shown in Figure 4. This indicates that a solvent extraction using ethanol can yield phytochemicals that possess insulin-mimetic/sensitizing properties that cannot be extracted using water. A study by Kar et al. (2003) stated that the antidiabetic and glucose uptake enhancement effect of the extract of Trichosanthes cucumerina could be due to a number of essential minerals $(\mathrm{Ca}, \mathrm{Zn}, \mathrm{K}, \mathrm{Mn}$ and $\mathrm{Cr})$ which are known to be associated with the mechanisms of insulin release. Several studies have suggested that calcium may play a role in the regulation of abdominal fat mass in obese people while zinc is involved in glucometabolic disorders (Suliburska et al., 2014). It has been also shown that insulin secretion may be improved by a highpotassium state and reduced potassium concentration may stimulate the renin-angiotensin-aldosterone system,

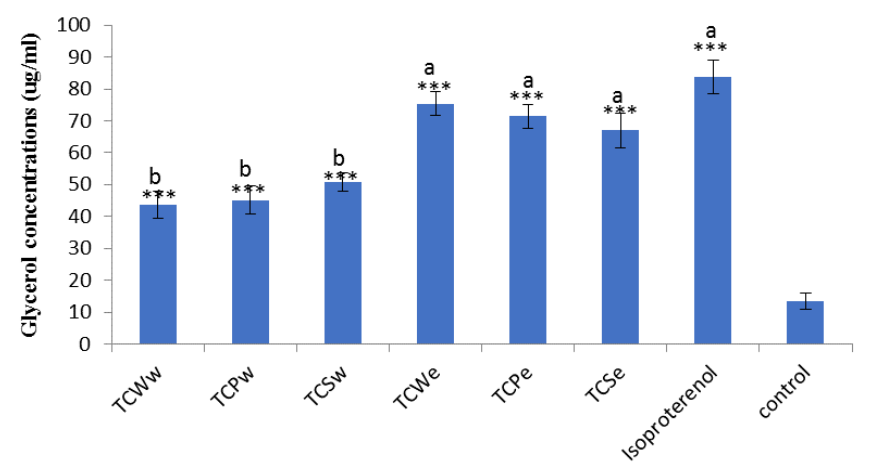

Figure 3. Effect of Trichosanthes cucumerina water and ethanol extracts on glycerol release (adipolysis) $(\mathrm{n}=3, *=\mathrm{p}<$ $0.05, * *=\mathrm{p}<0.01, * * *=\mathrm{p}<0.001)$.

and the latter has been associated with deterioration in peripheral insulin sensitivity (Martini et al., 2010).

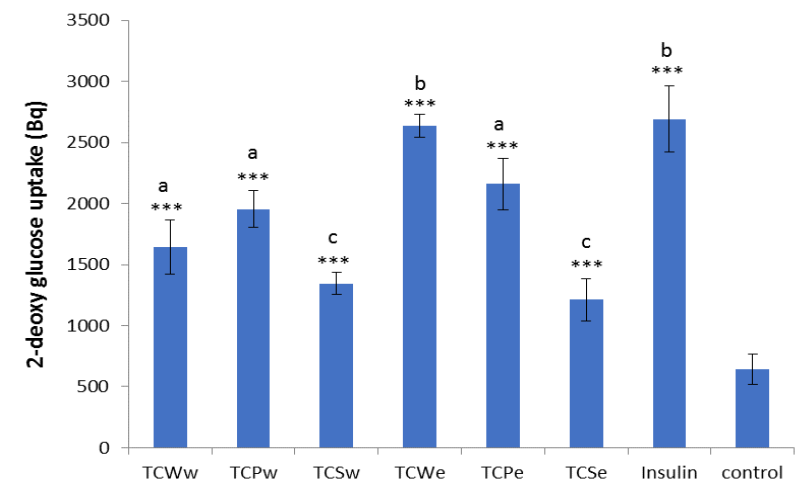

Figure 4. Effect of Trichosanthes cucumerina water and ethanol extracts on glucose uptake in 3T3-L1 adipocytes $(\mathrm{n}=3, *=\mathrm{p}<0.05, * *=\mathrm{p}<0.01, * * *=\mathrm{p}<0.001)$ 
Manganese plays an important role in the activity of insulin and its main function is to activate enzyme hexokinase and increase glucose uptake into the cells while its deficiency may result in a state of hypoglycemia. On the other hand, the role of chromium has been observed in the potentiation of the actions of insulin by increasing the insulin signaling pathway, blunting the negative-regulators of insulin signaling, enhancing AMPK activity, up-regulating cellular glucose uptake (Hua et al., 2012). A study by Arawwawala et al. (2009) reported that the hypoglycemic and antihyperglycemic activities for the extracts of Trichosanthes cucumerina could possibly be due to the synergistic effect of their polyphenol and flavonoid content through multiple effects involving both pancreatic and extra-pancreatic mechanisms. This claim could be backed by a study by Adebooye (2008) who demonstrated the high amounts of polyphenols and flavonoids especially in the whole extract of TC which could have been behind the high glucose uptake effect as shown in Figure 4 (TCWe, TCPe). Ethanol is known to be an excellent solvent for both acidic and basic constituents that helps to get a wide range of compounds from different polarities. Water extracts (TCWw, TCPw) showed significant yet lower effects on glucose uptake compared to ethanol extracts especially in the extracts of the peels (TCPw, TCPe), this could suggest that the nutrients responsible for the glucose sensitizing/ mimicking effect could be found in the peels of the vegetable. The insulin-mimicking activities of Cucurbitaceae extracts can also be due to their phytochemical content according to Patel et al. (2012) where phytochemicals such as terpenoids, alkaloids, polyphenols, flavonoids, and some other categories such as sugar derivatives have shown antidiabetic properties through the insulin-mimicking activity and in certain cases could be due to other extra-pancreatic mechanisms.

\subsection{Adiponectin and leptin assay}

Trichosanthes cucumerina extracts significantly $(\mathrm{p}<0.001)$ stimulated adiponectin secretion (TCPw, TCSw and TCSe) as shown in Figure 5 and slightly decreased leptin concentrations in 3T3-L1 adipocytes especially for the water extracts (TCPw, TCSw) as shown in Figure 6. There have been no studies showing the effect of Trichosanthes cucumerina extracts on adiponectin and leptin concentrations in 3T3-L1 adipocytes however, there have been some studies on Momordica charantia which belongs to the same family and shares similar phytochemical composition with Trichosanthes cucumerina, these studies revealed that the enhancement of glucose uptake and insulin-mimetic properties of Cucurbitaceae plants can be due to their high contents in triterpenoids and cucurbitacins (Roffey et al., 2007). Since the highest stimulation was observed in the ethanol extracts of the peels and seeds (TCP,
TCS), this could suggest that the compounds responsible for the increase in adiponectin secretion could be mainly found in the seeds (at higher amounts) and peels of the vegetable using a solvent extraction. A study by Müllner et al. (2014) reported that polyunsaturated fatty acids (PUFA) and vitamin E play an important role in increasing adiponectin secretions, and according to a study by Kim et al. (2012), the analysis of several Cucurbitaceae extracts revealed the presence of high amounts of PUFA as well as high amounts of

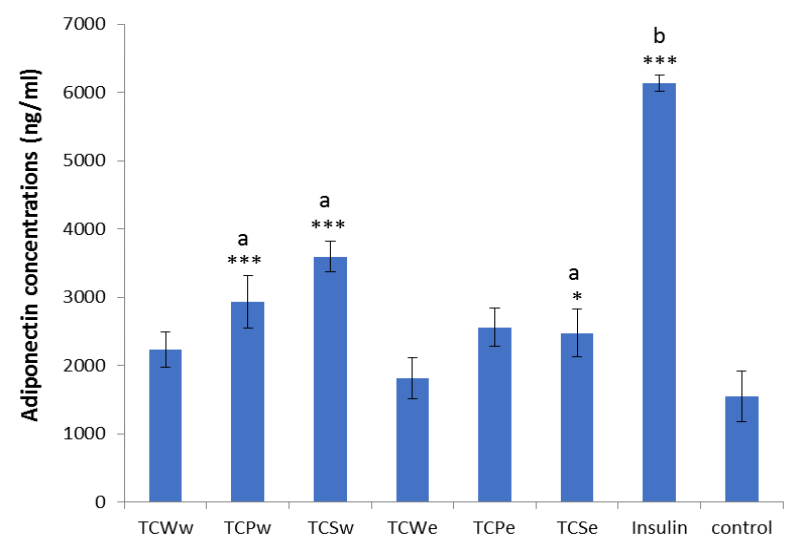

Figure 5. Effect of Trichosanthes cucumerina water and ethanol extracts on adiponectin concentrations in 3T3-L1 adipocytes $(\mathrm{n}=3, *=\mathrm{p}<0.05, * *=\mathrm{p}<0.01, * * *=\mathrm{p}<0.001)$.

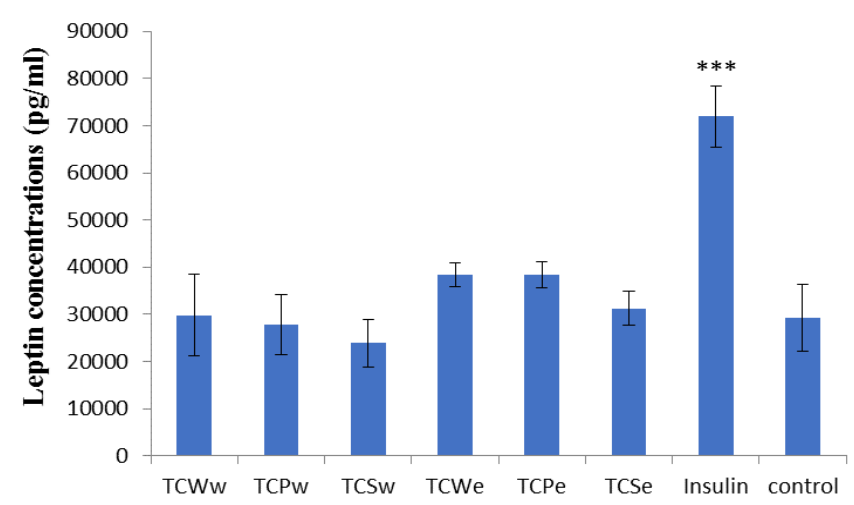

Figure 6. Effect of Trichosanthes cucumerina water and ethanol extracts on leptin concentrations in 3T3-L1 adipocytes $(\mathrm{n}=3, *=\mathrm{p}<0.05, * *=\mathrm{p}<0.01, * * *=\mathrm{p}<0.001)$.

monounsaturated fatty acids (MUFA), in addition to high amounts of vitamin $\mathrm{E}$ ( $\alpha$-tocopherol and $\gamma$-tocopherol) especially in the seeds. As for the low leptin concentrations, a study by Hsu and Yen (2007) reported that antioxidants such as flavonoids play a role in decreasing leptin levels and increasing adiponectin levels in 3T3-L1 adipocytes through the inhibition of the expression of PPAR $\gamma$ (Peroxisome proliferator-activated receptor gamma) and EBP (enhancer-binding proteins) levels. This was backed up by a study by Jeong et al. (2015) which suggested that the decrease in leptin levels in 3T3-L1 adipocytes could be due to the suppression of the mRNA expression of PPAR $\gamma$ caused by the presence of triterpenoids which are abundant in Cucurbitaceae vegetables. This was contradictory to a study by Tsuda $e t$ al. (2004) which showed that flavonoids (such as anthocyanins) induced an increase in leptin levels in cell 
medium of isolated rat adipocytes as was the case with our study findings in the ethanol extracts (TCWe, TCPe and TCSe). Additional studies need to be performed on the effect of Cucurbitaceae extracts on leptin regulation which could clarify the specific mechanisms by which it is regulated.

\section{Conclusion}

On the basis of the results obtained in the present study, it is concluded that the extracts of Trichosanthes cucumerina had a beneficial effect on 3T3-L1 adipocytes where they significantly stimulated adipocytes differentiation (adipogenesis), increased glycerol and free fatty acids release (adipolysis), stimulated glucose uptake in an action similar to insulin, in addition to increasing adiponectin concentrations and decreasing leptin concentrations which are adipokines responsible for energy homeostasis in adipocytes that have been linked to insulin resistance. The peel extracts (TCPw, $\mathrm{TCPe}$ ), as well as the seed extracts (TCSw), showed better stimulation in the majority of the parameters studied which should be extensively investigated to determine the nutrient profile and specific compounds responsible to determine the mechanisms by which they intervene. In conclusion, it was evident that Trichosanthes cucumerina extracts could possess insulin -mimicking/insulin sensitizing properties and should be further investigated for antihyperglycemic and antihyperlipidemic properties for the prevention and/or treatment of metabolic disorders such as diabetes and obesity.

\section{Conflict of interest}

The authors declare that there is no conflict of interest.

\section{Acknowledgments}

This research work was funded by International Islamic University of Malaysia Research Endowment Fund (REF) (EDW B 12-326-0804).

\section{References}

Adebooye, O.C. (2008). Phyto-Constituents and AntiOxidant Activity of the Pulp of Snake Tomato (Trichosanthes Cucumerina L.). African Journal of Traditional, Complementary, and Alternative Medicines, 5(2), 173-179. https://doi.org/10.4314/ ajtcam.v5i2.31270

Arawwawala, M., Thabrew, I. and Arambewela, L. (2009). Antidiabetic activity of Trichosanthes cucumerina in normal and streptozotocin-induced diabetic rats. International Journal of Biological and
Chemical Sciences, 3(2), 287-296. https:// doi.org/10.4314/ijbcs.v3i2.44504

Chen, Q., Chan, L.L.Y. and Li, E.T.S. (2003). Bitter melon (Momordica charantia) reduces adiposity, lowers serum insulin and normalizes glucose tolerance in rats fed a high fat diet. The Journal of Nutrition, 133(4), 1088-1093.

Chunduri J.R. (2013). Antioxidant and nutritional analysis of edible Cucurbitaceae vegetables of India. International Journal of Bioassays, 2(8), 1124-1129.

Floch, M.H. and Hong-Curtiss, J. (2002). Probiotics and Functional Foods in Gastrointestinal Disorders. Current Treatment Options in Gastroenterology, 5 (4), 311-321. https://doi.org/10.1007/s11938-0020054-6

Gry, J., Søborg, I. and Andersson, H.C. (2006). Cucurbitacins in plant food. Copenhagen, Denmark: Nordic Council of Ministers.

Harmon, A.W. and Harp, J.B. (2001). Differential effects of flavonoids on 3T3-L1 adipogenesis and lipolysis. American Journal of Physiology - Cell Physiology, 280(4), C807-C813.

Hsu, C.L. and Yen, G.C. (2007). Effects of flavonoids and phenolic acids on the inhibition of adipogenesis in 3T3-L1 adipocytes. Journal of Agricultural and Food Chemistry, 55(21), 8404-8410. https:// doi.org/10.1021/jf071695r

Hu, F.B. (2011). Globalization of Diabetes: The role of diet, lifestyle, and genes. Diabetes Care, 34(6), 1249 -1257. https://doi.org/10.2337/dc11-0442

Hua Y., Clark S. and Ren J., (2012). Molecular Mechanisms of Chromium in Alleviating Insulin Resistance. Journal of Nutritional Biochemistry, 23 (4), 313-319. https://doi.org/10.1016/ j.jnutbio.2011.11.001

Jeong, S.-J., Yoo, S.-R., Seo, C.-S. and Shin, H.-K. (2015). Traditional medicine yanggyuksanhwa-tang inhibits adipogenesis and suppresses proliferatoractivated receptor gamma expression in 3T3-L1 cells. Pharmacognosy Magazine, 11(43), 502-508. https://doi.org/10.4103/0973-1296.160456

Kader, A. (2001). Importance of Fruits, Nuts, and Vegetables in Human Nutrition and Health. Perishables Handling Quarterly, 106, 4-6

Kar, A., Choudhary, B. and Bandyopadhyay, N. (2003). Comparative evaluation of hypoglycaemic activity of some Indian medicinal plants in alloxan diabetic rats. Journal of Ethnopharmacology, 84, 105-108. https:// doi.org/10.1016/S0378-8741(02)00144-7

Kaushik, U., Aeri, V. and Mir, S.R. (2015). Cucurbitacins - An insight into medicinal leads from nature. Pharmacognosy Review, 9(17), $12-18$. https://doi.org/10.4103/0973-7847.156314

Kim, M.Y., Kim, E.J., Kim, Y.-N., Choi, C. and Lee, B.- 
H. (2012). Comparison of the chemical compositions and nutritive values of various pumpkin (Cucurbitaceae) species and parts. Nutrition Research and Practice, 6(1), 21-27. https:// doi.org/10.4162/nrp.2012.6.1.21

Martini, L.A., Catania, A.S. and Ferreira, S.R.G. (2010). Role of vitamins and minerals in prevention and management of type 2 diabetes mellitus. Nutrition Reviews, 68(6), 341-354. https://doi.org/10.1111/ j.1753-4887.2010.00296.x

Meerloo, J.V., Kaspers, G.J.L. and Cloos, J. (2011). Cell sensitivity assays: the MTT assay. Methods in Molecular Biology (Clifton, N.J.), 731, 237-245. https://doi.org/10.1007/978-1-61779-080-5 20

Mujahid, M.Z., Agistia, D.D. and Sa, M. (2013). A combination of bitter gourd ethanolic extract with ant lion larvae aqueous extract for a blood glucoselowering agent. International Food Research Journal, 20(2), 851-855.

Müllner, E., Plasser, E., Brath, H., Waldschütz, W., Forster, E., Kundi, M. and Wagner, K.-H. (2014). Impact of polyunsaturated vegetable oils on adiponectin levels, glycemia and blood lipids in individuals with type 2 diabetes: a randomised, double-blind intervention study. Journal of Human Nutrition and Dietetics: The Official Journal of the British Dietetic Association, 27(5), 468-478. https:// doi.org/10.1111/jhn. 12168

Newby, P.K. (2009). Plant foods and plant-based diets: Protective against childhood obesity? American Journal of Clinical Nutrition, 89(5), 1572-1587.

Nielsen, T.S., Jessen, N., Jorgensen, J.O.L., Moller, N. and Lund, S. (2014). Dissecting adipose tissue lipolysis: molecular regulation and implications for metabolic disease. Journal of Molecular Endocrinology, 52(3), R199-R222. https:// doi.org/10.1530/JME-13-0277

Patel, D.K., Prasad, S.K., Kumar, R. and Hemalatha, S. (2012). An overview on antidiabetic medicinal plants having insulin mimetic property. Asian Pacific Journal of Tropical Biomedicine, 2(4), 320-330. https://doi.org/10.1016/S2221-1691(12)60032-X

Rayalam, S., Della-Fera, M.A. and Baile, C.A. (2008). Phytochemicals and regulation of the adipocyte life cycle. The Journal of Nutritional Biochemistry, 19 (11), 717-726. https://doi.org/10.1016/ j.jnutbio.2007.12.007

Riss, T.L., Moravec, R.A., Niles, A.L., Duellman, S., Benink, H.A., Worzella, T.J. and Minor, L. (2004). Cell Viability Assays Assay Guidance Manual. In Assay Guidance Manual, p. 1-23. Bethsheda: Eli Lily \& Company and the National Center for Advancing Translational Sciences

Rizzatti, V., Boschi, F., Pedrotti, M., Zoico, E., Sbarbati,
A. and Zamboni, M. (2013). Lipid droplets characterization in adipocyte differentiated 3T3-L1 cells: size and optical density distribution. European Journal of Histochemistry, 57(3), e24. https:// doi.org/10.4081/ejh.2013.e24

Roffey, B.W.C., Atwal, A.S., Johns, T. and Kubow, S. (2007). Water extracts from Momordica charantia increase glucose uptake and adiponectin secretion in 3T3-L1 adipose cells. Journal of Ethnopharmacology, 112(1), 77-84. https:// doi.org/10.1016/j.jep.2007.02.003

Roleira, F.M.F., Tavares-da-Silva, E.J., Varela, C.L., Costa, S.C., Silva, T., Garrido, J. and Borges, F. (2015). Plant derived and dietary phenolic antioxidants: anticancer properties. Food Chemistry, 183, 235-258. https://doi.org/10.1016/ j.foodchem.2015.03.039

Saboo, S.S., Thorat, P.K., Tapadiya, G.G. and Khadabadi, S.S. (2013). Ancient and recent medicinal uses of Cucurbitaceae family. International Journal of Therapeutic Applications, 9, $11-19$.

Tsuda, T., Ueno, Y., Aoki, H., Koda, T., Horio, F., Takahashi, N., Kawada, T. and Osawa, T. (2004). Anthocyanin enhances adipocytokine secretion and adipocyte-specific gene expression in isolated rat adipocytes. Biochemical and Biophysical Research Communications, 316(1), 149-157. https:// doi.org/10.1016/j.bbrc.2004.02.031

Wang, Z., Wang, J. and Chan, P. (2013). Treating type 2 diabetes mellitus with traditional chinese and Indian medicinal herbs. Evidence-Based Complementary and Alternative Medicine, 2013. https:// dx.doi.org/10.1155/2013/343594

Yamamoto, N., Ueda, M., Sato, T., Kawasaki, K., Sawada, K., Kawabata, K. and Ashida, H. (2011). Measurement of glucose uptake in cultured cells. Current Protocols in Pharmacology, 55, 12.14.112.14.22. https://doi.org/ 10.1002/0471141755.ph1214s55.

Zaklos-Szyda, M., Majewska, I., Redzynia, M. and Koziolkiewicz, M. (2015). Antidiabetic Effect of Polyphenolic Extracts from Selected Edible Plants as alpha-Amylase, alpha -Glucosidase and PTP1B Inhibitors, and beta Pancreatic Cells Cytoprotective Agents - A Comparative Study. Current Topics in Medicinal Chemistry, 15(23), 2431-2444. https:// doi.org/10.2174/1568026615666150619143051

Zebisch, K., Voigt, V., Wabitsch, M. and Brandsch, M. (2012). Protocol for effective differentiation of 3T3L1 cells to adipocytes. Analytical Biochemistry, 425 (1), 88-90. https://doi.org/10.1016/j.ab.2012.03.005 
